\title{
Papillary Carcinoma in Thyroglossal Cyst: an Unusual Case
}

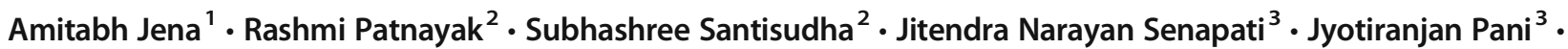 \\ Adya kinkara Panda ${ }^{4}$
}

Received: 17 June 2018 / Accepted: 3 March 2019 / Published online: 15 March 2019

(C) Indian Association of Surgical Oncology 2019

\begin{abstract}
Malignancy developing in thyroglossal cysts is very rare. Papillary carcinoma is the most common histopathological type of carcinoma encountered in thyroglossal cysts followed by squamous cell carcinoma. A 50-year-old male presented with a midline neck swelling. After ultrasonography and fine needle aspiration cytology, he underwent Sistrunk operation for removal of the thyroglossal cyst. The histopathology was reported as papillary carcinoma of the thyroid. So, he underwent total thyroidectomy, which showed foci of papillary microcarcinoma. Clinical awareness of this rare condition is essential for proper management. Possibility of malignancy arising in thyroglossal cysts should be considered in elderly patients.
\end{abstract}

Keywords Thyroglossal cyst $\cdot$ Papillary carcinoma of thyroid $\cdot$ Sistrunk's procedure $\cdot$ Total thyroidectomy

\section{Introduction}

Thyroglossal duct cysts are the most common congenital thyroid developmental abnormality during childhood. Few cases of thyroglossal cysts are diagnosed in adults. Malignancy in thyroglossal cyst is very rare (less than $1 \%)[1,2]$. Often, the diagnosis is incidental [3]. Papillary carcinoma is the most common histopathological type. They are more common in females and usually present in the third decade of life [2-4]. Many authors are of the opinion that well-differentiated thyroid carcinoma of the thyroglossal duct can be managed adequately by Sistrunk operation, whereas others recommend total thyroidectomy for papillary carcinoma $[1,2,4,5]$. We present a case of papillary carcinoma of a thyroglossal duct cyst in a 50-year-old male.

Rashmi Patnayak

rashmipatnayak2002@yahoo.co.in

1 Department of Surgical Oncology, Institute of Medical Sciences and SUM Hospital, Bhubaneswar, Odisha, India

2 Department of Pathology, Institute of Medical Sciences and SUM Hospital, Bhubaneswar, Odisha, India

3 Department of Surgery, Institute of Medical Sciences and SUM Hospital, Bhubaneswar, Odisha, India

4 Department of Radiology, Institute of Medical Sciences and SUM Hospital, Bhubaneswar, Odisha, India

\section{Case History}

A 50-year-old male noticed a midline neck swelling for 2 months. The swelling was moving with deglutition and protrusion of tongue. Clinically, it was diagnosed as a thyroglossal cyst. The thyroid profile report was within normal limit. Ultrasonography of the neck revealed a cystic lesion with partially calcified mural nodule. The thyroid gland was reported as normal (Fig. 1a). He underwent fine needle aspiration cytology (FNAC) which was reported as benign (Bethesda category II) in an outside hospital; afterwards, the slides were reviewed and the review report was suspicious of malignancy (Bethesda category V). All other routine laboratory investigations were within the normal limit. He underwent Sistrunk operation for thyroglossal cyst. The gross specimen showed a cystic structure with whitish mass measuring $1.5 \times 1 \mathrm{~cm}$ (Fig. $1 \mathrm{~b}$ ). The histopathology revealed a cyst lined by flattened cuboidal epithelium and neoplastic component of papillary carcinoma of the thyroid characterized by papillae with lining of cuboidal epithelium exhibiting mild pleomorphism and ground-glass appearance of nuclei with nuclear grooving (Fig. $1 \mathrm{c}, \mathrm{d}$ ). There was the presence of dystrophic calcification and two adjacent reactive lymph nodes. The final histopathological diagnosis was papillary carcinoma of the thyroid. Following this, the patient underwent further surgery to remove the thyroid which showed the presence of papillary microcarcinoma. The patient had an uneventful post-operative period. Afterwards, the patient was referred for radio-iodine ablation therapy. 
Fig. 1 a Ultrasonography of the neck showing a cystic lesion with partially calcified mural nodule. $\mathbf{b}$ Gross specimen showing cystic structure with whitish mass. c Histopathology of the thyroglossal cyst lined by flattened cuboidal epithelium and neoplastic component of papillary carcinoma of the thyroid with foci of dystrophic calcification. $\mathbf{d}$ Neoplastic papillae lined by cuboidal epithelium with nuclei exhibiting ground-glass appearance

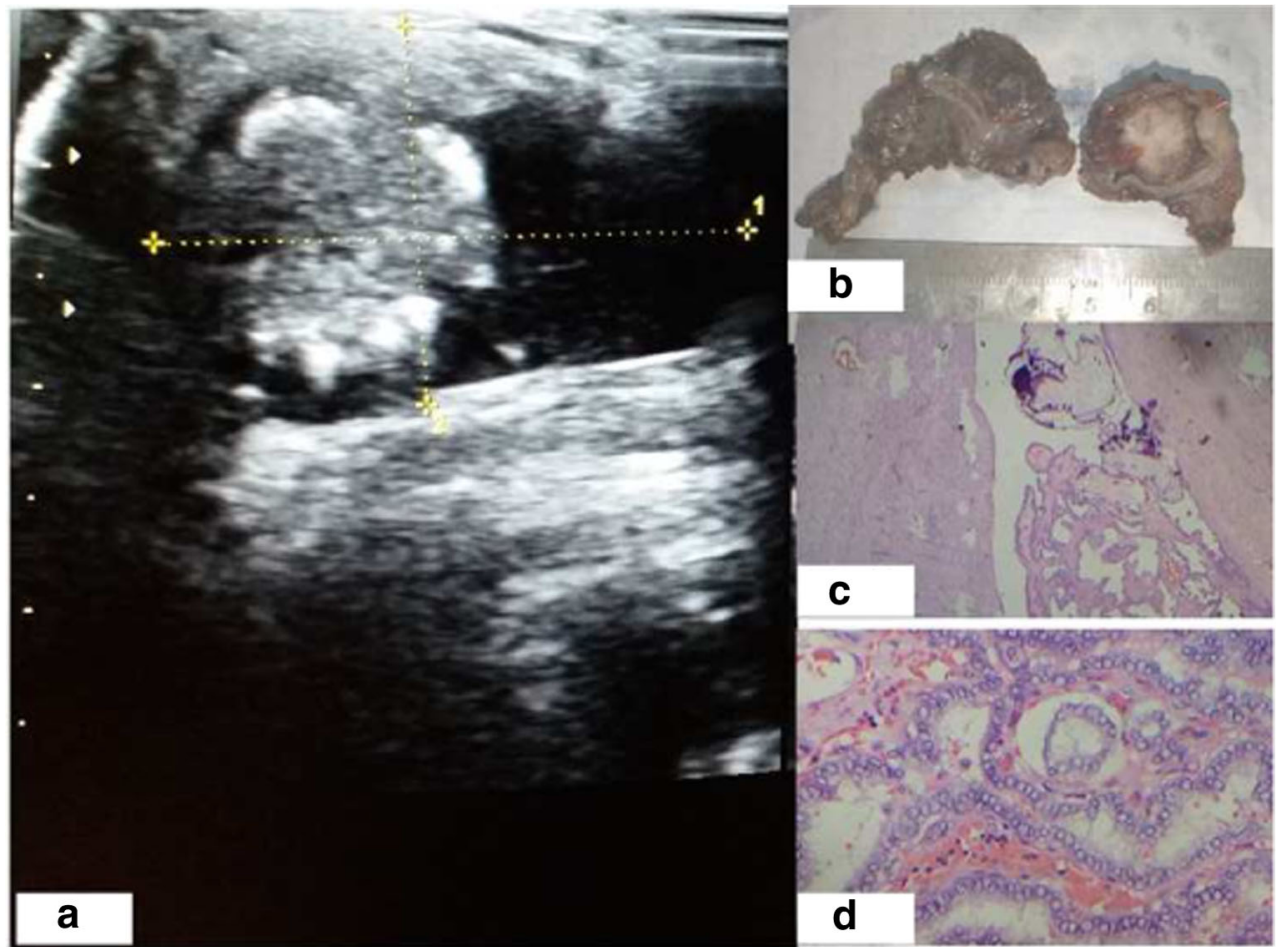

\section{Discussion}

Thyroglossal duct cysts are the most common developmental congenital anomalies in the thyroid. It is seen in around $7 \%$ of the adult population [2]. But carcinomas are extremely rare in thyroglossal duct cysts accounting for 0.7 to $1 \%$ of cases [2]. A majority (90\%) of them originate from ectopic thyroid tissue in the wall of the thyroglossal cyst, with papillary carcinoma being the most common malignancy [1].

Regarding the origin of thyroglossal duct adenocarcinomas, two theories exist. The first theory, which is also the most acceptable one, suggests the de novo origin, as in a majority of cases, ectopic thyroid tissue can be identified histopathologically $[1,2]$. The second theory is the metastatic theory which suggests that thyroglossal cyst carcinoma is metastatic from an occult primary in the thyroid gland. But this theory is less likely as multicentricity and multifocal growths are common in papillary thyroid carcinomas [1].

Ultrasonography is an essential initial diagnostic modality for midline neck swellings. The radiologic findings indicating malignancy are the presence of a mural nodule within a cystic lesion, microcalcifications, and the presence of enlarged cervical lymph nodes. FNAC is considered the most reliable method for the detection of malignancy in midline neck masses prior to surgery [6]. Since a majority of lesions are cystic in nature, FNAC of the mural nodule under ultrasound guidance can improve the diagnostic accuracy by reducing the false-negative results $[2,7,8]$.
The treatment options for carcinoma of the thyroglossal duct cyst include excision of the cyst, Sistrunk operation, and Sistrunk operation along with total thyroidectomy [9]. Sistrunk procedure is considered the standard surgical treatment for benign thyroglossal duct cysts as well as for malignancies with low-risk features. The 10-year survival rates of the patients undergoing simple cyst excision and Sistrunk operation are about $75 \%$ and $100 \%$ respectively. Patients with high-risk features should undergo total thyroidectomy along with a Sistrunk operation with or without cervical lymphadenectomy, depending on the involvement of cervical nodes. This should be followed by radioactive iodine ablation using iodine-131 $\left({ }^{131} \mathrm{I}\right)$ and thyroid-stimulating hormone (TSH) suppression thereafter. The high-risk features include patients above 45 years of age, prior history of radiation exposure, tumors larger than $1.5 \mathrm{~cm}$, invasion of the cyst wall, tumor in the thyroid gland on imaging, and the presence of cervical lymphadenopathy $[2,10]$.

Balalaa $\mathrm{N}$ et al. and Falvo $\mathrm{L}$ et al. have recommended total thyroidectomy for differentiated thyroid malignancy in a thyroglossal cyst irrespective of involvement of the thyroid either clinically or radiologically $[1,5]$. In our case, the thyroglossal cyst showed papillary carcinoma of the thyroid and the total thyroidectomy specimen revealed papillary microcarcinoma, thereby suggesting multifocality. Similar to our case, synchronous papillary carcinoma in thyroglossal duct cysts and the thyroid gland has been described in literature [9]. 
The prognosis of papillary carcinoma arising in the thyroglossal duct cyst is excellent compared to squamous cell carcinomas which have the worst prognosis. Follow-up is required and consists of history and physical examination, sonography of the neck, and whole-body scintigraphy.

\section{Conclusion}

Even though malignancy in thyroglossal cyst is very rare, it should be suspected in elderly patients. FNAC under ultrasound guidance can help in sampling the mural nodule associated with the cystic lesions. Clinical awareness of this rare condition is important as proper preoperative evaluation can be done which plays a role in deciding the nature of surgical treatment in these patients.

\section{Compliance with Ethical Standards}

Conflict of Interest The authors declare that they have no conflict of interest.

\section{References}

1. Balalaa N, Megahed M, Ashari MA, Branicki F (2011) Thyroglossal duct cyst papillary carcinoma. Case Rep Oncol 4: 39-43. https://doi.org/10.1159/000324405

2. Sudharsanan S, Vijayakumar C, Dharanya S, Elamurugan T, Manwar AS (2017) A rare case of carcinoma in the thyroglossal duct cyst of an elderly patient. Cureus 9:e1365. https://doi.org/10. $7759 /$ cureus. 1365

3. Aggarwal H, Wadhera S, Raikwar RS, Shukla S, Mathur RK (2007) A rare case of incidentally diagnosed primary papillary carcinoma of thyroglossal duct cyst. Indian J Surg 69:145-146. https://doi.org/ 10.1007/s12262-007-0006-4

4. Zivaljevic V, Bozic V (2006) Papillary carcinoma in a thyroglossal duct cyst. Acta Chir Belg 106:252-253

5. Falvo L, Giacomelli L, Vanni B, Marzollo A, Guerriero G, De Antoni E (2006) Papillary thyroid carcinoma in thyroglossal duct cyst: case reports and literature review. Int Surg 91:141-146

6. Jena A, Patnayak R, Vaikkakara S, Sachan A, Lakhmi AY (2016) Malignancy in thyroid nodule - preoperative role of ultrasound and fine-needle aspiration cytology. Thyroid Res Pract 13:45

7. Jena A, Patnayak R, Prakash J, Sachan A, Suresh V, Lakshmi AY (2015) Malignancy in solitary thyroid nodule: a clinicoradiopathological evaluation. Indian J Endocr Metab 19: 498-503

8. Choi YM, Kim TY, Song DE, Hong SJ, Jang EK, Jeon MJ (2013) Papillary thyroid carcinoma arising from a thyroglossal duct cyst: a single institution experience. Endocr J 60:665-670. https://doi.org/ 10.1507/endocrj.EJ12-0366

9. Cherian MP, Nair B, Thomas S, Somanathan T, Sebastian P (2009) Synchronous papillary carcinoma in thyroglossal duct cyst and thyroid gland: case report and review of literature. Head Neck 31: 1387-1391. https://doi.org/10.1002/hed.21029

10. Plaza CP, Lopez ME, Carrasco CE, Meseguer LM, Perucho A (2006) Management of well-differentiated thyroglossal remnant thyroid carcinoma: time to close the debate? Report of five new cases and proposal of a definitive algorithm for treatment. Ann Surg Oncol 13:745-752

Publisher's Note Springer Nature remains neutral with regard to jurisdictional claims in published maps and institutional affiliations. 